$\xi=-{ }^{2}$

\title{
Formulation, physicochemical evaluation and antimicrobial ac- tivity of green toothpaste on streptococcus mutans
}

\author{
Joel Ogboji $^{1}{ }^{*}$, I. Y. Chindo ${ }^{1}$, Aliyu Jauro, D. E. A. Boryo ${ }^{1}$, Lawal N. M. ${ }^{1}$ \\ ${ }^{1}$ Chemistry Department Abubakar Tafawa Balewa University Bauchi, Bauchi State, Nigeria. \\ *Corresponding author E-mail: registrar@atbu.edu.ng
}

\begin{abstract}
Background: Toothpaste is a cosmetic product with increasing relevance and demand. However most commercial toothpaste consist of complex chemicals whose health safety remain unclear.

Objectives: The present work involves the formulation, and comparative physicochemical evaluation and antimicrobial activity of green toothpaste and three commercial toothpastes (Close-Up, Oral-B and Dabur-Herbal)

Methods: The green toothpaste were formulated using Tumeric (Curcuma longa), Aloe Vera (Aloe barbadensis miller), Guava (Psidium guajava), Mint (Mentha piperita), Neem (Azadirachta indica), and Lemon (Citrus lemon) as the active ingredients and comparatively evaluated for various properties like colour, taste, odor, texture, abrasivity, spreadability, cleansing ability, foaming ability, stability, homogeneity, moisture content, gritty matter and $\mathrm{pH}$. The antimicrobial activity of the formula was comparatively tested on Streptococcus mutans (the major causative organism of dental caries).

Results: Cold extracts of plant materials with ethanol showed a relative low (3.6\% - 6.8\%) percentage recovery of bioactive compounds. Physico-chemical tests revealed that the spreadability, $\mathrm{pH}$, foam, gritty matter and homogeneity gave favourable results that compares well with commercial ones. The result of the antimicrobial test shows significant difference between the mean zones of inhibition of the various toothpastes.

Conclusion: The results of the study agree with traditional application of the herbaceous plants and showed that the formulated toothpaste contains phytochemicals which possess antimicrobial properties and may be safer compared to toothpaste consisting of synthetic chemicals.
\end{abstract}

Keywords: Antimicrobial Activity; Bioactive; Cosmetic Product; Streptococcus Mutant, Toothpaste

\section{Introduction}

Dental care seeks to address problems such as bad breath, tooth decay, periodontal (gum disease), tooth sensitivity and dental caries arising from microbial activities in the oral cavity (Sharma). At present, dental caries is one of the common diseases in the world. The major causative organism of dental caries is Streptococcus mutan. It acts by converting carbohydrates to acid which combine with food debris and saliva to form plaque on the surface of the tooth (Satcher 2000). Under this condition the mouth $\mathrm{pH}$ shift to below 5.5 and demineralization of the teeth begins. Continuous demineralization at a particular site over a period of time results in formation of cavity at the site. Dental disease could be painful in some severe cases and the pain can be worsened by heat, cold or sweet food and drinks (Taylor 2004, Dwivedi et al. 2011).

The incorporation of synthetic chemical agents with antimicrobial property into cosmetic products like toothpaste is a critical issue confronting our world today because of their adverse effect on human health (Bowen 2004). Medicinal plants are good reservoir of antimicrobial agents and can serve as alternative to synthetic chemicals reported to have adverse effects like cancer, DNA damage, hypersensitivity reaction and teeth staining (Carounanidy 2007, Groppo 2008). According to the Physician Desk Reference, the mucosal lining inside of the mouth has an absorption efficiency of over $90 \%$ (Maltz and Beighton 2012). Consequently toothpaste may never be swallowed but can be absorbed within seconds through the skin on the lip or through the mucous membrane in the mouth. Under physiological conditions, oral fluids such as saliva and biofilm fluid contain Calcium (Ca) and Phosphate (P) in supersaturated concentrations relative to the mineral composition of enamel. Therefore these $\mathrm{Ca}$ and $\mathrm{P}$ ions are constantly deposited on the enamel surface or are redeposited on areas of the enamel where there are lost. This is a natural mechanism promoted by the saliva to preserve the mineral structure of enamel in the mouth (Cury et al. 2009).

The acid produce by bacterial metabolism from sugar decreases the $\mathrm{pH}$ of dental plaque and consequently the biofilm fluid becomes unsaturated of $\mathrm{Ca}$ and $\mathrm{P}$ and dissolution of the enamel set in (fig1) (Cury and Tenuta 2008,Naumova et al. 2010). The use of toothpaste containing fluoride increases the concentration of fluoride in the oral cavity. The presence of this fluoride in the biofilm fluid, combine with $\mathrm{Ca}$ and inorganic $\mathrm{P}$ release by dissolved Hydroxyapatite result in the formation of Fluoroapatite. When Fluoroapatite is incorporated by enamel (at $\mathrm{pH}$ higher than 4.5) it reduces enamel dissolution (Cury and Tenuta 2008).

During sugar exposure a critically low $\mathrm{pH}$ is observed but when the exposure ceases, the $\mathrm{pH}$ value returns to physiological values permitting the enamel to incorporate Fluoroapatite (Naumova, 2010). 


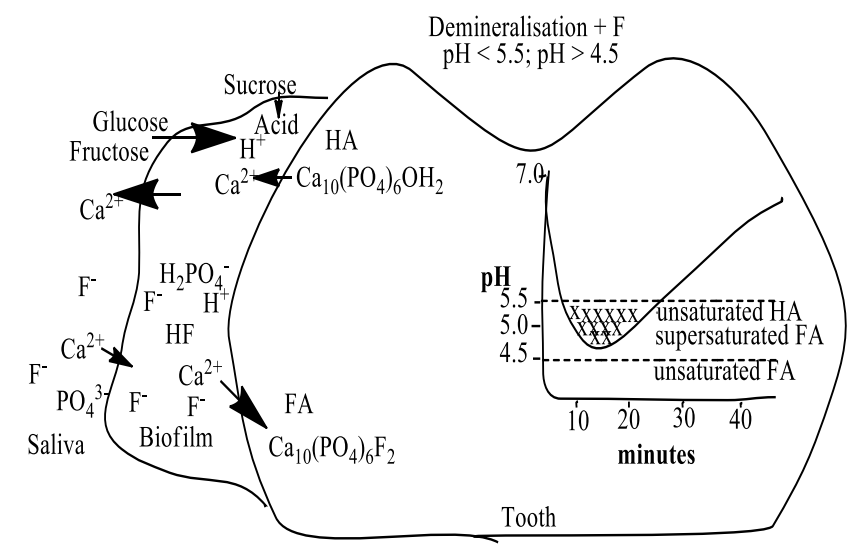

Fig. 1: Enamel Demineralisation in the Presence of Fluoride F in Dental Biofilm.

Sugar undergoes a transformation to acid in the biofilm, when the $\mathrm{pH}$ is lower than 5.5, unsaturation with regards Hydroxyapatite (HA) is reached inside the biofilm fluid, dissolution of minerals thus occurs. However at $\mathrm{pH}$ higher than 4.5 in the presence of fluoride, supersaturation of Fluoroapatite (FA) occurs in the biofilm fluid, resulting to the reprecipitation of minerals in the enamel. Therefore the net demineralisation is decreased (Cury and tenuta 2008, Cury et al. 2009).

Additionally, saliva containing fluoride demonstrate enhance ability to remineralise enamel (Cury and Tenuta 2008). Saliva fluoride kinetics rely upon different factors, flow rate, age, stimulation effects, properties of fluoride compound, volume and application time of the fluoride compound. The interaction among these factors influences the process in which fluoride in oral cavity is cleared (Naumova et al. 2010). The potential of fluoride to harden enamel surfaces and boost remineralisation at $\mathrm{pH}$ higher than 5.5 has been shown and the supersaturated conditions mentioned above are restored (fig 2) (Bartlett 2007). In a nutshell, the presence of fluoride in the oral environment allow for small amount of $\mathrm{Ca}$ and in inorganic $\mathrm{P}$ lost initially by enamel under low $\mathrm{pH}$ to be efficiently recovered in the form of both hydroxyapatite and fluoroapatite (Cury and Tenuta 2008, and Naumova et al. 2010). However the amount of $\mathrm{Ca}$ and $\mathrm{P}$ recovered is lower than that lost, resulting in a net small mineral lost (Naumova et al. 2010).

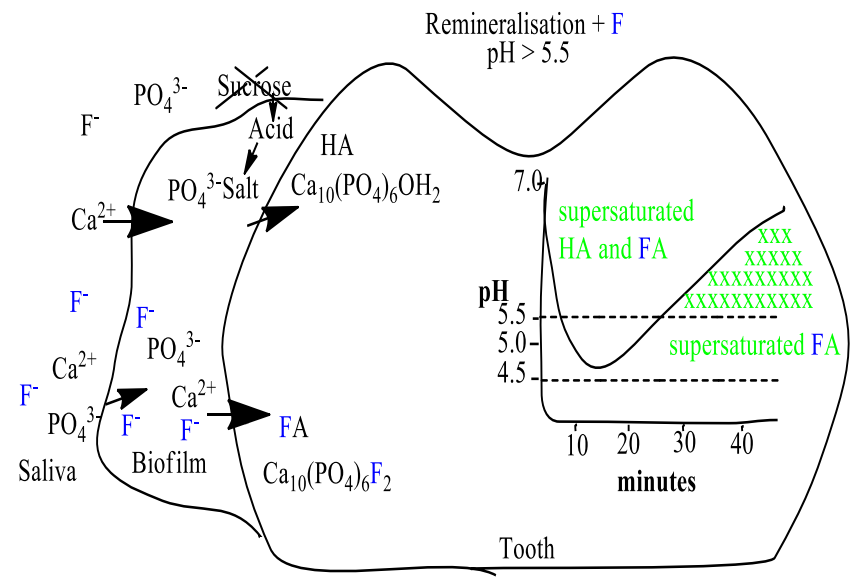

Fig. 2: Enamel Remineralisation in the Presence of Fluoride (F) in Dental Biofilm.

When exposure to sugar ceased, the acid in the biofilm is remove by the saliva and converted to salts. Consequently, a $\mathrm{pH}$ of 5.5 and above is reached and the biofilm fluid becomes supersaturated with HA and FA, as a result, $\mathrm{Ca}$ and $\mathrm{P}$ lost by enamel dissolution van be more efficiently recovered if the biofilm still contain the fluoride (Cury and Tenuta 2008 and Cury et al. 2009)

The fluoride release in the oral cavity during tooth brushing is stored on the enamel surface and the remaining dental biofilm, primarily as Calcium-Fluoride $\left(\mathrm{CaF}_{2}\right)$ like deposits (Negri and Cury 2002, Cury and Tenuta 2008).

Although many chemical anticaries agents are available commercially, the search for an effective natural alternative is still on. The green toothpaste is the composition of tuber of Curcuma long, stem of Aloe barbadensis miller, leaves of Psidium guajava, Mentha piperita, Azadirachta indica, and Citrus lemon, Acacia Senegal (Table 1). Streptococcus mutans is the bacteria strain used in the antimicrobial study.

\section{Materials and methods}

\subsection{Materials}

The different plant materials, Closed-Up, Oral-B and DaburHerbal toothpaste were purchased from Muda-Lawal market in Bauchi, Bauchi State, Nigeria. Deionized water was used throughout the study.

Table 1: Composition of Green Toothpaste

\begin{tabular}{lc}
\multicolumn{2}{c}{ Table 1: Composition of Green Toothpaste } \\
\hline Components & Amount \\
\hline Tumeric extract & $5 \mathrm{~g}$ \\
Aloe-vera extracts & $5 \mathrm{~g}$ \\
Guava extracts & $5 \mathrm{~g}$ \\
Neem extracts & $5 \mathrm{~g}$ \\
Balsam extracts & $5 \mathrm{~g}$ \\
Activated Charcoal & $2 \mathrm{~g}$ \\
Calcium carbonate & $4 \mathrm{~g}$ \\
Gum Arabic & $35 \mathrm{~g}$ \\
Lime juice & $5 \mathrm{ml}$ \\
Coconut oil & $6 \mathrm{ml}$ \\
Mint oil & $6 \mathrm{ml}$ \\
Honey & $20 \mathrm{ml}$ \\
Deionized water & $15 \mathrm{ml}$ \\
\hline
\end{tabular}

\subsection{Methods}

\subsubsection{Cold extraction}

The leaves of the plants were washed lightly to remove dirt's, dried for four weeks in the shade to avoid chemical degradation due to sunlight. The dried leaves and dried turmeric tubers were separately pulverized using electric blender. $150 \mathrm{~g}$ of powdered plant were separately subjected to cold extraction in $70 \%$ ethanol at ambient temperature with occasional agitation for five days. The mixture was filtered and the filtrate concentrated by evaporation at $45^{\circ} \mathrm{C}$. The extracts were dried and stored in air-tight containers in the refrigerator at $4^{\circ} \mathrm{C}$ until later use. The percentage recovery was calculated as: (mass of extract x 100\%)/mass of powdered plant.

\subsubsection{Green toothpaste formulation procedure}

The procedure requires a slow but efficient incorporation of soluble and insoluble components into the main water phase. Accurate quantity of Gum Arabic was dissolved with deionized water to form a thick smooth uniform paste in a mortal with pestle. Honey was added with continuous trituration till gel was formed. Calcium carbonate was added slowly to the above mixture with continuous stirring to mix well. Dried extract of the herbaceous plants prepared previously was incorporated with thorough mixing. Balsam fruit powder was dissolved in lime juice and added to the mixture. Mixed well. Finally mint and coconut oil were added to mask the taste and give flavor.

\subsubsection{Composition of the conventional toothpastes tested}

The composition of Oral-B, Dabur Herbal and Close-Up toothpastes were determined by visual inspection of the package label.

\subsubsection{Physicochemical evaluation}

Each procedure was repeated for each of the toothpaste tested 


\subsubsection{Organoleptic parameters}

Organoleptic parameters (colour, taste, odor, texture) were evaluated by sensory and visual inspection.

\subsubsection{Moisture content}

$5 \mathrm{~g}$ of toothpaste was heated in an oven at $105^{\circ} \mathrm{C}$ for 24 hours. It was allowed to cool and reweighed. The heating and reweighing process continued until a constant weight was recorded in consecutive checks. The weight loss was used to calculate the moisture content using the formula.

$\%$ Moisture $=$ Original sample weight - Dry sample weight $\times 100$ $\%$

\subsubsection{Cleaning ability}

Eggshells contain high amount of calcium and most approximate tooth enamel for testing cleaning ability of toothpastes. One eggshell was used for each toothpaste tested. $200 \mathrm{ml}$ of water was heated to boiling in a beaker. $15 \mathrm{ml}$ and 20 drops of vinegar and red food colouring were added respectively. A hard-boiled egg was immersed in the food colouring solution for 5 minutes until it is stained with red colour. Using a permanent marker, a line was drawn along the length of the eggshell dividing it in half. A toothbrush moistens with distilled water and the water shaken off was used to brush one side of the egg for 10 strokes (each stroke was a complete back and forth motion). The egg was inspected for any colour removal. The toothbrush was rinsed with water and the water shaken off, a pea-sized amount of formulated toothpaste was placed on the toothbrush and the brush was used to brush one side of the egg for 10 strokes. The egg was rinsed and inspected for colour removal. The procedure was repeated for each toothpaste that was tested.

\subsubsection{Foaming ability}

$5 \mathrm{~g}$ of toothpaste was weighed into a $100 \mathrm{ml}$ glass beaker. $10 \mathrm{ml}$ of distilled water was added to it and allowed to stand for 30 minutes (this allows the toothpaste to disperse in the water). The contents of the beaker were stirred and the slurry was transferred to a $250 \mathrm{ml}$ graduated measuring cylinder. The residue in the beaker was rinsed and transferred with further $5-6 \mathrm{ml}$ portion of water to the cylinder. The contents of the cylinder were stirred to ensure a uniform suspension. The cylinder was stoppered and subjected to 12 complete shakes. The cylinder was allowed to stand for 5 minutes and the volume of foam calculated as:

Foaming ability $=\mathrm{L}_{1}-\mathrm{L}_{2}$

$\mathrm{L}_{1}=$ volume in $\mathrm{ml}$ of foam with water

$\mathrm{L}_{2}=$ volume in $\mathrm{ml}$ of water only

\subsubsection{Spread ability}

About $1 \mathrm{~g}$ of formulated toothpaste was placed in the centre of a glass plate and a second glass plate placed over it. A $1 \mathrm{~kg}$ weigh was carefully placed on top of the set up and allowed for 10 minutes. The weight was removed and the diameter of the paste was measured in $\mathrm{cm}$.

\subsubsection{Stability}

Some quantity of the toothpastes were transferred into each of 3 glass test tubes and stoppered. The test tubes were heated at $45^{\circ} \mathrm{C}$ for 72 hours, allowed to cool and content examine visually for homogeneity, signs of fermentation and other deterioration results were reported as pass or fail.

\subsubsection{PH}

$10 \mathrm{~g}$ of toothpaste was dissolved in $10 \mathrm{ml}$ of deionised water, stirred well to make a suspension in a $100 \mathrm{ml}$ beaker. The $\mathrm{pH}$ was measured with Janway $3510 \mathrm{pH}$ meter.

\subsubsection{Abrasiveness}

A pea size amount of formulated toothpaste was placed on a clean plastic microscope slide and a drop of distilled water added. A clean cotton swab was rubbed on the toothpaste sample in a back and forth motion 30 times using short strokes. The slide was carefully rinsed and dried with soft tissue. The slide was examined under a dissecting microscope illuminated from above. The number of scratches on the surface of the slide were determined and rated on a scale of 0 (no scratch) to 5 (high degree of scratches).

\subsubsection{Gritty matter}

Small amount of the toothpaste was rubbed into a piece of butter paper. The number and intensity of scratches that appear on the butter paper was recorded as absent or present.

\subsubsection{Homogeneity}

At room temperature normal force was applied on the tube containing the toothpaste at room temperature and observed if the paste extrude homogeneously from the tube.

\subsubsection{Antimicrobial test}

\subsubsection{Selection of patients}

Patients within the age bracket 10-14 possessing high carries experience were selected. These patients had no record of use of chemical anti-plaque agent prior to two days of the study initiation.

\subsubsection{Collection of saliva}

The patients were asked to rinse their mouth with water, the accumulated saliva in the floor of the mouth after two minutes were collected into an uricol rubber bottle. This was done in the early morning time and immediately transported to the laboratory.

\subsubsection{Antimicrobial evaluation of toothpastes}

Three conventional toothpastes together with the formulate toothpaste were selected for assessment of their antimicrobial activities. The selected toothpastes dilution were made by mixing $1 \mathrm{~g}$ in measured $4 \mathrm{ml}$ of distilled water to give solution 1 , a $1: 4(\mathrm{~g} / \mathrm{v})$ dilution. Serial dilutions were made by mixing $1 \mathrm{ml}$ of solution 1 in $4 \mathrm{ml}$ of distilled water to give solution 2. The same procedure was repeated with 2 to give solution 3. Disk diffusion method was employed. This method is normally used for testing the effect of drugs on bacteria, therefore a better choice for this study. $6 \mathrm{~mm}$ diameter punched filter papers were sterilized and soaked in the different dilution samples. The papers were then placed over the media with Streptococcus Mutans. The plates were incubated in an upright position at $37 \mathrm{oC}$ for 24 hours. The zones of inhibitions were measured in $\mathrm{mm}$. All plates were made in triplicates.

\section{Results and discussion}

\subsection{Results}

The results obtained from the study are presented in the tables below.

The result of percentage recovery of ethanol is shown in table 2 . Overall, extract of Balsam fruit gave the highest recovery $(6.8 \%)$ while Aloe Vera gave the lowest recovery (3.6\%) (Table 2). 
Table 2: Percentage Recovery of 70\% Ethanol Extract from 150g Powder of Plants Leaves

\begin{tabular}{lllllc}
\hline & Guava & Neem & Aloe Vera & Tumeric & Balsam Fruit \\
\hline Amount of Extract (g) 9.6 & 7.8 & 5.4 & 7.2 & 10.2 \\
Recovered (\%w/w) & 6.40 & 5.20 & 3.60 & 4.80 & 6.80 \\
Appearance & Dark Green Green & White & Yellow & Dark brown \\
\hline
\end{tabular}

The composition of the formulated toothpaste varies significantly from the conventional ones (Table 3 )

Table 3: Toothpastes Compositions

\begin{tabular}{l}
\hline Toothpastes Composition as listed on packages \\
\hline O Sorbitol, Aqua, Hydrated Silica, Sodiumlaurylsulfate, Aroma, Cellu \\
lose Gum, Disodium Phosphate, Sodium Phosphate, Saccharin, Sodium \\
Fluoride, Caromed, Limonene,C119140, Eugenol, C1 42090
\end{tabular}

Fluoride, Caromed, Limonene,C119140, Eugenol, C1 42090

D Natural lemon extract, Mint, Eucalyptus, Rosemary, Chamomile, Sage, Myrrh, Sorbitol, Silica, Treated water, Poly ethylene glycol 1500,

Sodiumlaurylsulfate, Sodium Carboxyl, Methyl cellulose, Sodium saccharin, Disodium ortho phosphate

F Tumeric, Aloe-Vera, Guava, Neem, lime, Coconut oil, Honey, Balsam fruit,Activated Charcoal, Calcium carbonate, De-ionize water, Gum Arabic, Mint,Chitosan.

C Sorbitol, Aqua, Hydrated silica, Sodiumlaury sulphate, PEG-32, Aroma, Cellulose Gum, Sodium saccharin, Sodium fluoride, Zinc sulphate, Mica, Sodium hydroxide, Glycerine, Eugenol, Cl 12490, Cl 16035, Cl 17200, Cl 77491, Cl 77891

F: Formula, D: Dabur-Herbal, O: Oral-B, C: Close-Up

The formula and their conventional version were comparatively studied for their different physicochemical properties and changes on the surface of the ename (Table 4).

Table 4: Comparative Organoleptic and Physicochemical Evaluation of Toothpastes

\begin{tabular}{lllll}
\hline Test & \multicolumn{1}{c}{ F } & C & D & \multicolumn{1}{c}{ O } \\
\hline Color & dull green & Red & Green & Blue \\
Taste & Bitter & Sweet & Sweet & Sweet \\
Odor & Pleasant & Pleasant & Pleasant & Pleasant \\
Texture & Smooth & Smooth & Smooth & Smooth \\
Abrasiveness & 2.0 & 3.0 & 3.0 & 3.0 \\
Spread ability $(\mathrm{cm})$ & 8.0 & 6.5 & 7.0 & 6.5 \\
pH & 8.8 & 7.5 & 8.0 & 7.2 \\
Foam $(\mathrm{cm})$ & 30 & 53 & 51 & 52 \\
Stability & Pass & Pass & Pass & Pass \\
Moisture content & (\%)35.83 & 30.81 & 29.98 & 30.10 \\
Gritty matter- & Absent & Absent & Absent & Absent \\
Homogeneity & Pass & Pass & Pass & Pass \\
Cleansing & + & + & + & + \\
\hline \multicolumn{7}{l}{ (+): Presence, F: Formulated toothpaste: Oral-B, C: Close Up, D: Dabur }
\end{tabular}

$(+)$ : Presence, F: Formulated toothpaste: Oral-B, C: Close Up, D: Dabur herbal toothpaste

All toothpastes in the study have shown antimicrobial effect. The ability of $\mathrm{C}, \mathrm{O}$ and $\mathrm{D}$ to retain its antimicrobial activity even at high dilution of 2 and 3 is remarkable. This might be due to the present of fluoride in their formulation. Most toothpaste products contain fluoride as active ingredients because it helps in caries prevention (Table 5, Fig. 3).

Table 5: Antimicrobial Activity Zone of Inhibition (Mm) Dilutions

\begin{tabular}{lccc}
\hline Toothpastes & 1 & 2 & 3 \\
\hline F & 16.12 & 7.33 & 2.11 \\
D & 13.33 & 9.19 & 2.78 \\
O & 14.87 & 13.00 & 7.67 \\
C & 15.41 & 3.51 & 9.00 \\
\hline
\end{tabular}

F: Formula, D: Dabur-Herbal, O: Oral-B, C: Close-Up

antimicrobial activities of test samples

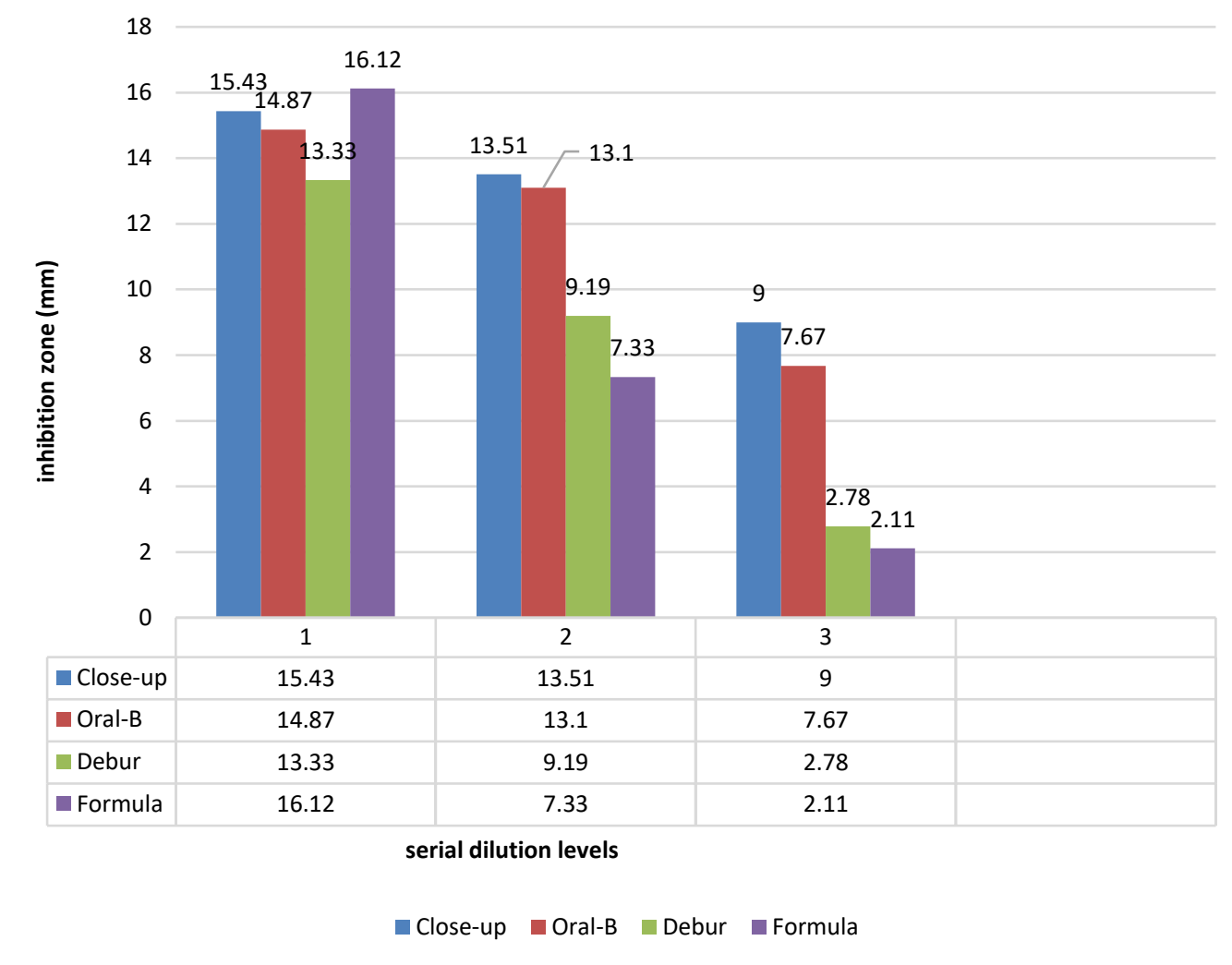

Fig.3: Antimicrobial Activity of Toothpastes. 


\subsection{Discussion}

\subsubsection{Percentage recovery}

The result of percentage recovery of ethanol is shown in table 2 . Overall, extract of Balsam fruit gave the highest recovery $(6.8 \%)$ while Aloe Vera gave the lowest recovery (3.6\%) (Table2).

The amount of extracts recovered from the plants varies and this variability agrees with similar results of Hsu B. 2006. This suggests evidence of differences in the availability of extractable components as a result of varied chemical composition of the plants (Hsu et al. 2006). Generally the percentage recovery of the crude extracts were found to be very low and might become further lower if they were to be obtained in their pure state. This indicates that the concentration of these bioactive components is very low in plants.

\subsubsection{Physicochemical tests}

The formula and their conventional version were comparatively studied for their different physicochemical properties and changes on the surface of the enamel.

All toothpastes have a sweet taste except $\mathrm{F}$ which has a faint bitter taste due to its high herbal extracts composition. The sweet taste is due to the synthetic sweetener constituent. The odour and texture of all tested toothpastes are pleasant and smooth respectively (table 4). These properties of the toothpastes enhance marketability.

F show a dull green colour in appearance suggesting the presence of plant extracts and absent of colour dye, although D is green, it contain some colour dye together with the plant extracts. $\mathrm{C}$ and $\mathrm{O}$ are glossy red and blue respectively (Table 4).

Several studies that evaluates the relationship between the abrasive potential of toothpaste and alteration on enamel have reveal that the less the abrasive potential of toothpaste, the less enamel get worn out (Joiner et al. 2008, Vieira et al. 2005, Andrade et al 1998, Whitehead et al. 1996), however the higher the abrasive potential the better the stain removal, in the present study the formulated toothpaste has the lowest abrasive potential. F is the only toothpaste containing Calcium Carbonate in its composition. (Table 3) Toothpaste with this composition are less abrasive (Redmalm, G 1986). Hydrated silica is the abrasive in C, O and D (table 3). Reports from previous studies have shown that silica exhibit strong abrasive properties that can increase the roughness of the enamel (Vieira et al.2005).

Spreadability is a measure of how well the products can penetrate different areas following application. High spreadability guarantees high chances of wide range performance. $\mathrm{F}$ has the highest spreadability (table 4). The $\mathrm{pH}$ values were different among the toothpastes, however the $\mathrm{pH}$ in all the five products were in the alkaline region. An alkaline $\mathrm{pH}$ causes less adverse change to the dental surface. This shows that $\mathrm{pH}$ is a very important factor when formulating these products.

The foaming ability show different values among the toothpaste products, this suggest differences in concentration of the detergent (SLS) commonly used in toothpaste. While $\mathrm{F}$ whose composition is detergent free gave a low foaming value, $\mathrm{C}$ gave a high foaming value (table 4) indicating it has higher concentration of detergent in its composition than all the other toothpastes. One major concern about detergent in toothpaste according to ADA is increased oral irritation among canker sores prone people and therefore toothpaste without SLS is a better choice.

All toothpastes showed ability of cleaning the enamel irrespective of the absent or presence of detergent in their composition.

The stability test is a close approximate of the shelves life of the products. All products remain effective for months. Usually a sample stored at $45^{\circ} \mathrm{C}$ for 8 weeks is equivalent to one stored at room temperature for a year.

Moisture content test show that the composition of the toothpaste are different. D gave the lowest Moisture content and highest ash content (Table 4) indicating that this toothpaste on application to the teeth alters the surface of the enamel, since higher ash value is a sign of alteration in roughness (Redmalm 1986).

The gritty matter test helps to ascertain the presence of solid in the formulation. This is important as regular usage of formulation with gritty matter can wear off the teeth enamel and cause injury to skin. Gritty matters were absent in all tested toothpastes (Table $4)$.

All formulation tested for homogeneity pass. This indicated that obtaining the formulation from the tube by extrusion poses no difficulty.

\subsubsection{Antimicrobial test}

Dental plaque is characterized by complex microbial accumulation on tooth surface and subsequent destruction of enamel tissue. Consequently antimicrobial agent inclusion in toothpaste has become necessary. Antimicrobial agents kill microorganisms by disrupting their cell wall and inhibiting their enzymatic activity. They also slow multiplication and prevent bacterial aggregation (Bou-Chacra et al. 2005). Data from the present study support the assertion from several clinical studies that demonstrated the inhibitory effects of antimicrobial toothpastes on oral bacteria and gingiva (Fine et al. 2006)

All toothpastes in the study have shown antimicrobial effect (table 5). The ability of $\mathrm{C}, \mathrm{O}$ and $\mathrm{D}$ to retain its antimicrobial activity even at high dilution of 2 and 3 is remarkable (figure 3). This might be due to the present of fluoride in their formulation. Most toothpaste products contain fluoride as active ingredients because it helps in caries prevention (table 3 ). Although the ability of fluoride to inhibit dental caries is well documented (Marinho 2009), if the bacterial load is much it is not possible for fluoride to overcome the bacteria completely (Featherstone 2004). The antimicrobial effectiveness of fluoride toothpaste are concentration dependent (Fejerskov and Kidd 2003).

Toothpaste $\mathrm{F}$ is $93 \%$ plant based and exhibited least effectiveness at higher dilutions compare to other tested toothpastes. Modern medical practice have enjoyed significant beneficial contributions from herbal medicine (Almas et al. 2001). The present study show the herbal formulation to be equally as effective at high concentration as the fluoridated toothpastes, but not significantly superior to them. Bioactive compound like alkaloids, flavonoids, tannins and polyphenols are responsible for the antimicrobial activity of herbs. Several studies on plaque and gingivitis control by herbal base toothpaste are reported (Amrutesh et al. 2010, George et al. 2009). According to Moran 1991, herbal toothpastes have rarely been shown to have significantly superior anti-plaque activity than conventional pastes (Moran et al. 1991). Data from the present study are in agreement with his assertion.

Although the herbal toothpaste may not significantly be superior in antimicrobial activity to the conventional toothpastes comparatively tested, the tannins, saponins, and flavonoids present in it strengthens the periodontium, prevent gum inflammation and gingival tissues (Hussain et al. 2009, Igbinosa et al. 2009). The herbal toothpaste serve as good choice for children up to 3years of age to avoid fluoride toxicity as excess fluoride uptake from conventional toothpaste can cause dental fluorosis.

\section{Conclusion}

The results of the present study reveal toothpaste can be formulated from plant based materials. The study shows that the formulated toothpaste exhibits significant antimicrobial and cleaning property as do conventional toothpastes; however the formulated toothpaste exhibits less abrasiveness, sweetness, colour and surfactant properties.

The overall results of the research therefore provide convincing evidence of the satisfactory antimicrobial activity of the herbal formula. The research offers a significant contribution to make 
possible a way forward on how safe natural materials can replace the synthetic ingredients in cosmetic products.

\section{Acknowledgements}

I would like to first express my special thanks to God for the gift of a healthy life and my supervisors, Professor I.Y Chindo and Professor Aliyu Jauro. Their doors were always open whenever I encounter a trouble spot or had some questions regarding my research. They consistently allowed this project to be my own work but guided me in the right direction. Also worth appreciating is Dr. Miss Boryo whose eyes for details has made this paper worthy of scholarly repute

\section{References}

[1] Almas, K. Dahlan, A. Mahmoud, A., Propolis as a natural remedy. (2001): An update. Saudi Dental Society. 13(1),45-9

[2] Amrutesh, S. Malini, J. Tandur, and P. S. Patki, P. S. (2010): Clinical evaluation of a novel herbal dental cream in plaque formation: a double blind, randomized, controlled clinical trial. Journal of experimental pharmacology. 2, 105-9

[3] Andrade Junior, A. C. C. Andrade, MRTC. Machado, WAS, Fisher, R. G. (1998): In vitro study of dentrifice abrasivity. Rev. Odontol University Sao Paulo. $12 \quad$ (13), https://doi.org/10.1590/S0103-06631998000300006.

[4] Bartlett, D. (2007): A new look at erosive tooth wear in elderly people. JADA 138: Volume 21-25. https://doi.org/10.14219/jada.archive.2007.0356.

[5] Bou-Chacra, N. A. Gobi S. S. Ohara, and M. T. Pinto, T. J. A (2005): Antimicrobial activity of four different dental gel formulas on cariogenic bacteria evaluated using the liner regression method.Revista Brasileira De Ciencias Farmaceuticas. 41 (3), 323-31 https://doi.org/10.1590/S1516-93322005000300005.

[6] Bowen W. H. (2004): do we need to be concern about dental caries in the coming millennium? Critical review of oral biology medicine. 13. 126-21

[7] Carounanidy U. A. (2007): use of an aqueous extract of terminalia chebula as an anticaries . indian journal of dental research. 18,15256 https://doi.org/10.4103/0970-9290.35823.

[8] Cury, J. A., Tenuta, L. A. (2008): How to maintain a Cariostatic Fluoride Concentration in the Oral Environment. Adv Dent Res. 20:13-16.

[9] Cury J. A., Oliveira, M. J. L., Martins C. C., Tenuta L. M. A., Paiva S. A. (2009) : Available Fluoride in Toothpastes Used by Brazilian Children. Braz Oral Res. 23 (Spec Iss 1):27-34.

[10] Dwivedi D, Kushwah T, Kushwah M, Singh V. (2011): Antibiotic susceptibility pattern against ppathogenic bacteria causing dental caries. South Asian Journal of experimental biology, 1, 32-35

[11] Featherstone, J. D. B. (2004): The Continuum of Dental CariesEvidence for a Dynamic Disease Process. Journal of Dental Research, $83 \quad$ (Special Issue), C39-C42. https://doi.org/10.1177/154405910408301s08.

[12] Fejerskov, O. Kidd, E. (2003): Dental caries, the disease and its clinical management. First ed. (London. Wiley Blackwell.

[13] Fine D. H., Furgang D., Markowitz K., Sreenivasan P. K., Klimpel K., De Vizio W. (2006): The antimicrobial effect of a triclosan/copolymer dentifrice on oral microorganisms in vivo. Journal of American Dental Association. 137 (10), 1406-13. https://doi.org/10.14219/jada.archive.2006.0053.

[14] George, J. Hegde, and S. Rajesh, K. S. Kumar A. (2009): The efficacy of a herbal-based toothpaste in the control of plaque and gingivitis: a clinico-biochemical study. Indian Journal Dent Res. 20(4), 480-2 https://doi.org/10.4103/0970-9290.59460.

[15] Groppo F. C. (2008): Use of phytotherapy in dentistry. Phytotherapy research. 22,993-98 https://doi.org/10.1002/ptr.2471.

[16] Hsu, B., Coupar, I. M., Ng, K. (2006): antioxidant activity of hot water extract from the fruit of the Doum Palm, Hyphaene thebiaca. Food Chem. 98, 317-328 https://doi.org/10.1016/j.foodchem.2005.05.077.

[17] Hussain, J. A. L. Khan, N. Rehman, M. Hamayun, Z. K. Shinwari, W. Malik, I. J. L. (2009) : Assessment of herbal products and their composite medicinal plants through proximate and micronutrients analysis. JournalMed. Pl. Res. 3(12), 1072-1077

[18] Igbinosa, O. O. Igbinosa, E. O. Aiyegoro, O. A. (2009) : Antimicrobial activity and Phytochemical screening of stem bark extracts from jatropha curcas (linn). African Journal Pharm. and pharmacol. 3(2), 058-062.

[19] Joiner, A. Pickles, M. J. Lynch, S. Cox, T. F. (2008): The measurement of enamel wear by four toothpaste. Int Dent. Journal. 58(1), 23-8 https://doi.org/10.1111/j.1875-595X.2008.tb00173.x.

[20] Maltz, M., Beighton, D. (2012): Multidisciplinary Research Agenda for Novel Antimicrobial Agent for Caries Prevention and Treatment. Adv Dent Res, (24), 133-136. https://doi.org/10.1177/0022034512453049.

[21] Marinho, V. C. (2009): Cochrane reviews of randomise trials of fluoride therapy for preventing dental caries. Eur Arch Paediatr dent. 10(3), 183-91 https://doi.org/10.1007/BF03262681.

[22] Moran, J. Addy, M. Newcombe, R. (1991): Comparism of a herbal toothpaste and a fluoride toothpaste on plaque and gingivitis. Clin Prev Dent. 13(3), 12-5

[23] Naumova, E. A., Gaengler, P., Zimmer, S., Arnold, W. H. (2010): Influence of Individual Saliva Secretion on Fluoride Bioavailability. The Open Dentistry Journal 4, 185-190. https://doi.org/10.2174/1874210601004010185.

[24] Negri, H. M. D., Cury, J. A. (2002): Efeito dose-resposta de uma formulação de dentifrício com concentração reduzida de fluoreto estudo in vitro. Pesqui Odontol Bras.16 (4): 361-365. https://doi.org/10.1590/S1517-74912002000400014.

[25] Sharma PP, Cosmetics, Formulation manufacture, quality control, $7^{\text {th }}$ ed. (Pardana publication pvt ltd) 507-19

[26] Redmalm, G. (1986): Dentrifice abrasivity. The use of laser light for determination of the abrasive properties of different silicas. An in vitro study. Swed Dent Journal. 10(6),243-50

[27] Satcher, S. G. (2000): Oral Health in America: A Report of the Surgeon General; U.S. Department of Health and Human Services: Washington, D. C.

[28] Taylor G. W. (2004): Diabetes, periodontal diseases, dental caries and tooth loss. A review of the literature. Compendium of continuing education in dentistry $25,179-188$

[29] Vieira, A. Ruben, J. L. Huysmans, M. C. (2005) : Effect of titanium tetrafluoride, amine fluoride and fluoride vanish on enamel erosion in vitro. Carie Res. 39(5), 371-9 https://doi.org/10.1159/000086843.

[30] Whitehead, S. A. Shearer, A. C. Watts, and D. C. Wilson, N. H (1996): Surface texture changes of a composite brush with tooth whitening dentrifices. Dent Mater.12 (5), 315-8. https://doi.org/10.1016/S0109-5641(96)80040-6. 